\title{
Squelettes désarticulés
}

Restes humains abandonnés et travail de réassociation

Disarticulated Bones: Abandoned Human Remains and the Work of

Reassociation

John Harries

\section{OpenEdition \\ Journals}

Édition électronique

URL : https://journals.openedition.org/tc/8197

DOI : $10.4000 /$ tc. 8197

ISSN : 1952-420X

Éditeur

Éditions de l'EHESS

Édition imprimée

Date de publication : 31 octobre 2016

Pagination : 448-451

ISBN : 9782713225291

ISSN : 0248-6016

Référence électronique

John Harries, «Squelettes désarticulés », Techniques \& Culture [En ligne], 65-66 | 2016, mis en ligne le 31 octobre 2016, consulté le 29 septembre 2022. URL : http://journals.openedition.org/tc/8197 ; DOI : https://doi.org/10.4000/tc.8197 


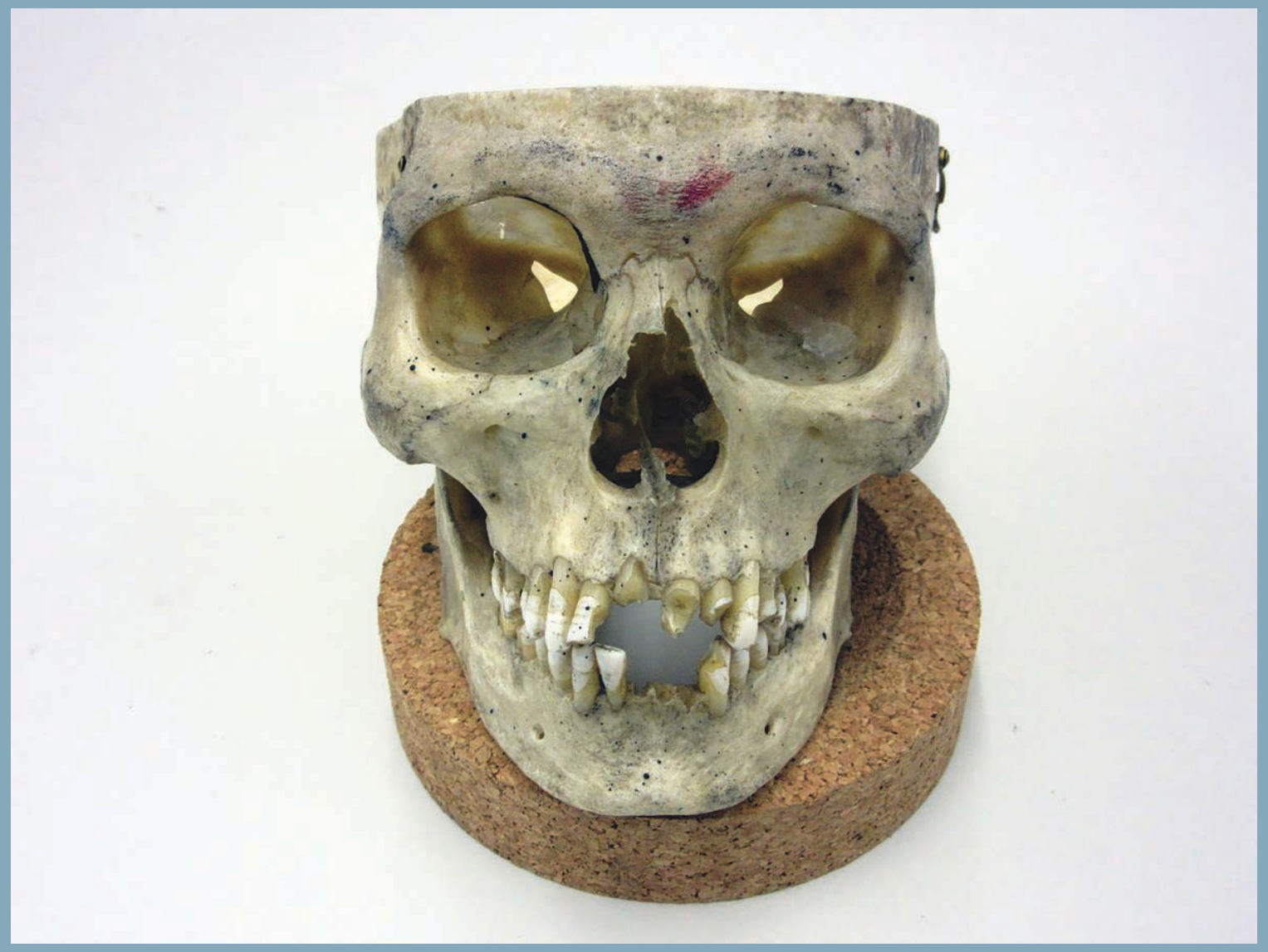




\section{Squelettes désarticulés}

\section{Restes humains abandonnés et travail de réassociation}

Cet article traite du projet intitulé The Bones Beneath the Face ("Les os sous le visage») mené par un collectif d'artistes, d'anthropologues et d'archéologues de l'Université d'Edimbourg. Au cœur de ce projet, une chose abandonnée. Un « déchet». Quelque chose dont on n’a plus besoin. Cette chose est un crâne humain trouvé dans les réserves du College of Art d'Edimbourg (ECA). L'objectif de notre projet a été de prendre ce crâne afin d'en faire quelque chose. En effet, il s'agissait de recycler, créer, diriger une série d'assemblages grâce auxquels ce crâne retrouverait sa valeur perdue.

Avant de commencer ces travaux de recyclage, il y avait ce crâne «abandonné ». Un crâne est sans conteste un type de déchet étrange, mais les restes humains oubliés ne sont pas si inhabituels qu'il n'y paraît. Nous vivons au beau milieu d'ossements délaissés. Beaucoup d'entre eux proviennent de l'époque où la mode chez les scientifiques consistait à collecter des ossements humains pour les étudier et les exhiber. À cette période ces ossements avaient été, au sens propre comme au figuré, assemblés au sein de systèmes complexes de valeurs et de pratiques enchevêtrées. Ils étaient littéralement articulés, en ce sens qu'ils étaient associés à d'autres éléments, d'autres os en vue de former un squelette, mais constituaient également des compositions étudiées de propos et d'artéfacts. Ils devenaient ainsi articulés, au sens figuré. Lorsqu'ils furent accrochés, les os commencèrent à exposer leur propre nature, les personnes qu'ils étaient autrefois, ou encore l'existence de races et de groupes ethniques.

Les temps changent. L'enthousiasme scientifiquement approuvé pour la collection d'ossements a été freiné par des préoccupations éthiques et rendu anachronique par des changements de paradigmes scientifiques; pourtant les os collectés des années auparavant et relégués dans les tréfonds les plus obscurs de notre culture commune perdurent. Ces ossements abandonnés sont devenus dés-articulés. Les assemblages dans lesquels ils étaient autrefois articulés ont aujourd'hui disparu. On peut encore voir des traces de leur vie antérieure lorsqu'ils étaient liés à d'autres os, d'autres idées, d'autres artéfacts, mais ces articulations sont désormais réduites à l'état de traces à peine perceptibles. Cependant, alors même qu'ils sont coupés de la structure à laquelle ils étaient 
rattachés et qui les rendaient articulés et intelligibles, les ossements humains gardent néanmoins cette présence affective qui évoque de façon métonymique ce qui a pu être dit autrefois.

En recyclant le crâne retrouvé à l'ECA, nous nous sommes engagés dans un projet - que nous poursuivons toujours aujourd'hui - consistant à recréer les «choses» articulées grâce à des techniques d'objectivation et/ou de subjectivation. Pour ce faire, nous avons intégré ces ossements dans de nouveaux assemblages en vue d'éliminer leur ambigüité et de les fixer en tant que formes de présence identifiable, ce qui peut les faire s'engager sur la voie d'une politique de reconnaissance de leur condition au sein des systèmes de valeurs existants. Ainsi, en prenant en compte l'existence d'os dés-articulés, nous sommes en réalité confrontés à ce problème, antérieur à un processus d'articulation et en évoquant la possibilité que cette curieuse forme de déchet, muette mais hantée par la mémoire du discours, puisse de nouveau retrouver une «voix».

Lobjet de notre projet portait sur le processus matériel de réassemblage de l'ensemble des éléments. En parallèle, nous avons également procédé à deux autres réassemblages. L’un a reposé sur une analyse ostéologique: grâce aux savoirs de Linda Fibiger, l'examen précis des dents a révélé, alors que la forme du crâne suggérait qu'il appartenait à un homme, qu'il s'agissait de la tête d'un adulte n'ayant pas vécu très vieux, peut-être même mort avant l'âge de trente ans. L'autre démarche a consisté en une installation interactive, intitulée The Bones Beneath the Face («Les os sous le visage »), d’après une idée de Jane Cheeseman, développée, conçue et « dirigée» par Joan Smith, John Harries, Joost Fontein et John Nowak, organisée en marge de l'assemblée 2014 de l'association à Edimbourg. Sur une table en bois, à la surface noire et abîmée, était posé un crâne isolé sur un socle. Sur une autre table similaire, une série d’objets était disposée: un bouquet de roses rouges en plastiques, une bouteille de Coca-Cola vide en verre, une vieille carte de l'Irlande, un crâne de mouton, des dents de requin, des coquillages, etc. Il a été demandé aux visiteurs de «prendre quelques minutes pour imaginer et percevoir ce qu'est ou a été ce crâne». Ensuite, choisissant un élément parmi la série d'objets, ils ont été invités à "créer une installation incluant le crâne ». Une photographie de la nature morte obtenue a été prise par Caroline Douglas et le visiteur a été encouragé à rédiger « une légende, ou toute autre chose qui serait appropriée à [son] installation».

Bien que différents, ces deux projets pourraient être considérés comme étant des expériences sur l'«herméneutique matérielle», c'est-à-dire les processus sociotechniques et perceptifs qui nous permettent de comprendre, percevoir ou ressentir la vie d'autres personnes à travers les vestiges de leur existence. L'analyse ostéologique et l'installation interactive, où des processus novateurs consistent à réarticuler ce qui a été désarticulé, à « déterrer» dans le sens où quelque «chose » a échappé à nos réseaux d'importance, est révélé et replacé au sein de ces réseaux, et, par l'intermédiaire des processus d'assemblages, acquiert la capacité de parler et d'être entendu. À travers ces travaux d'assemblage, et en particulier du geste de tourner le crâne de face, les ossements en sont venus à suggérer la mort et la brièveté de la vie, ou les possibilités d'une vie autrefois vécue, ou, de manière plus poignante encore, la vie de quelqu'un qu'on a connu et aimé.

Toutefois, même si le crâne a été réarticulé au sein du travail d'assemblage, ces procédés ont également fait apparaître un reste allant au-delà du travail de réassemblage et de revalorisation: ce crâne avec un aspect résolument «chosifié», à la fois insuffisant et excessif vis-à-vis de nos 
tentatives de l'articuler en tant que sujet/objet. Car ce qui a été assemblé est éphémère et finit par être désassemblé. Cet avant/après de la désarticulation hante l'unification des éléments et la territorialisation activée par le fait de positionner le crâne de face. Ainsi, alors même que la chose prend la parole, elle exprime ce qui ne peut être articulé.

\section{E n ligne}

Retrouvez l'article complet, en version originale (anglais), sur revues.org, Techniques\& Culture 65-66 « Réparer le monde. Excès, reste et innovation » : http://tc.revues.org.

\section{L'auteur}

John Harries est enseignant-chercheur en anthropologie sociale à l'université d'Édimbourg. Ses recherches portent sur la mémoire et la matérialité, avec une problématique particulière autour des questions identitaires contemporaines dans les sociétés dominantes postcoloniales.

\section{Iconographie}

Image d'ouverture. Crâne @ Joan Smith. 1. @ Caroline Douglas.

\section{Pour citer cet article}

Harries, J. 2016 «Squelettes désarticulés. Restes humains abandonnés et travail de réassociation », TechniquesE Culture 65-66 « Réparer le monde. Excès, reste et innovation», p. 448-451.

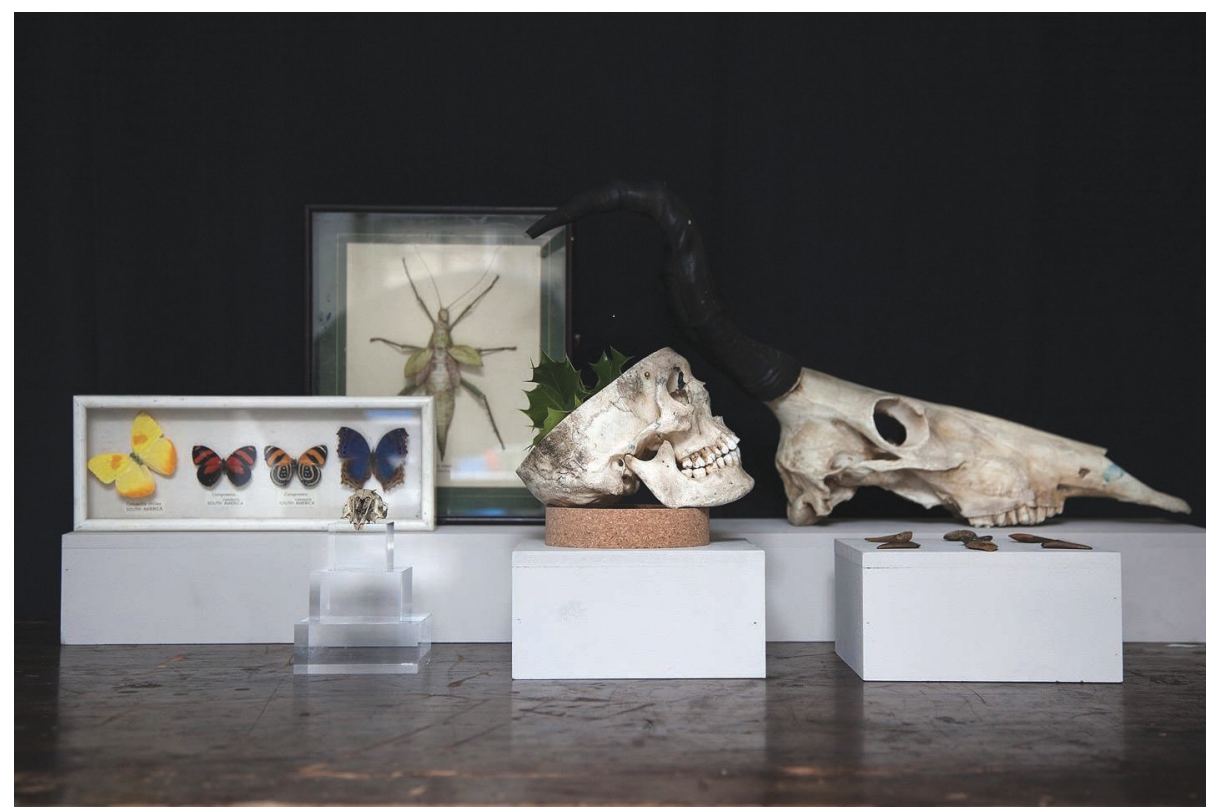

1. «We lived, felt dawn, saw sunset glow, loved and were loved..... In Flanders Fields, John McCrae. 